\title{
Antimicrobial Potential of Trichaptum Biforme and Bjerkandera Adusta from Pennsylvania, USA
}

\author{
John Chikwem $^{1} \quad$ Gbolagade Jonathan $^{1,2} \quad$ Anna Hull $^{1} \quad$ Michael Asemoloye $^{3 *} \quad$ Oluwole Osonubi $^{2}$ \\ Francis Omeonu ${ }^{2}$ \\ 1.Biology Department, 1570 Baltimore Pike, Lincoln University, Pennsylvania, USA. \\ 2.Mycology \& Applied Microbiology Unit, Department of Botany, University of Ibadan. Nigeria. \\ 3.School of Pharmaceutical Science and Technology, Health Science Platform, Tianjin University Nankai \\ District, Tianjin. China
}

\begin{abstract}
The antimicrobial potential of Trichaptum biforme and Bjerkandera adusta extracts were evaluated on some selected bacteria and Candida albicans. Our results showed that aqueous, methanol and ethanol extracts of $T$. biforme and B. adusta exhibited no antimicrobial activity against Candida albicans. However, some extracts of $B$. adusta were very effective against three Gram-negative bacteria (Escherichia coli, Salmonella typhimurium and Pseudomonas aeruginosa) and three Gram-positive bacteria (Staphylococcus aureus, Staphylococcus epidermidis and Bacillus cereus). Likewise, extracts of Trichaptum biforme were also effective against all three Gram-positive bacteria and only one Escherichia coli. The effectiveness of these two fungi as antibacterial agents should be well explored with development of optimized methods for mass production of these macrofungi in controlled environments.
\end{abstract}

Keywords: Macrofungi; extracts; bacteria; explored; effectiveness; optimized method

DOI: $10.7176 / \mathrm{JNSR} / 11-16-01$

Publication date:August $31^{\text {st }} 2020$

\section{Introduction}

Macrofungi like mushrooms, polypores, morels, auricularia and many other edible higher fungi have been used as food additives, condiments and spices for several thousand years [1-3]. These fungi which are good sources of dietary fiber, amino acids, vitamins and essential mineral elements $[4,5]$. Beside their use as food, they have also been employed for several medicinal purposes. Different antibacterial, antifungal, antioxidant, antiviral, anti-tumor, cytostatic, immunosuppressive, immunomodulatory, anti-allergic, anti-atherogenic, hypoglycemic, antimalarial, anti-inflammatory, hepatoprotective and insecticidal compounds have been isolated from mushrooms and other higher fungi [6-10].

Among all classes of fungi, fruit body types are usually found in Ascomycetes and Basidiomycetes. Anke [11] and Oluranti et al. [2] separately suggested that these fungal groups have not been sufficiently explored for the different types of chemotherapeutic agents that they contain. These authors reason that since bioactive compounds from mushrooms are numerous, they could be exploited as natural sources of new drugs. Many Ascomycetes and Basidiomycetes have been reported as producers of antibacterial, antifungal and insecticidal compounds, which they use to protect themselves against unwanted microorganisms and insects in their natural environments $[12,13]$. These bioactive compounds could therefore be isolated from edible, inedible and poisonous fungal species [14].

Medicinal fungi, especially mushrooms have been used from antiquity, especially by Asian and African traditional healers. In south Western Nigeria, traditional medical practitioners usually prepare hot water extracts of fungi with other medicinal plants, or they may use local gin for extraction $[15,16]$. Often times, they may also prepare their fungal-plant mixtures in powdered form. North American forests contain much of the world's biodiversity of higher fungi; therefore, the fungal kingdom in this continent represents a potential reservoir of fungal species with diverse potentials for food, medicines and other uses. Trichaptum biforme and Bjerkandera adusta are common American macrofungi which have not been well exploited for pharmacological and antimicrobial potentials.

Trichaptum biforme, a voracious decomposer of dead hardwood is one of the most commonly encountered wood-rotting fungi in the United States and Canada. This fungus which usually grows in clusters belongs to the Class, Basidiomycetes; Order, Hymenochaetales; and Family, Hymnochaetaceae [17]. It appears as a toothed fungus that produces a straw colored sapwood-rot in standing trees; it completely lacks stipe, but possesses a pileus of 2-6 cm diameter and 1-3mm thick. The sporocarp of this fungus is white in color, tough, leathery and inedible $[18,19]$. Bjerkandera adusta, popularly known as smoky polypore is a bracket fungus in the Class, Basidiomycetes; Order, Polyporales; and Family, Meruliaceae. Although, this fungus is a pathogen of living trees in which it causes white rot, it can also live as a saprobe on dead wood. It was formerly described as Boletus adustus, but this name was changed to Bjerkandera adusta in 2013 when its genome was sequenced [20]. It is widely distributed throughout North America including Canada. 
The emergence of drug resistant microorganisms has attracted the attention of scientists into the exploration of antimicrobial drugs from fungi and plants. Antimicrobial drug resistance is one the biggest threats to human existence. Pathogenic microorganisms of humans and animals are rapidly evolving mechanisms of resistance against existing antimicrobial agents due to the abuse, overuse and misuse of antimicrobial agents. This study was therefore carried out to explore the potential use of extracts of T. biforme and B. adusta as antimicrobial agents against Gram-positive and Gram-negative bacteria, and the fungus, Candida albicans.

\section{Methods and materials}

Two test fungi used in this study were Trichaptum biforme and Bjerkandera adusta. The fruit bodies were collected from the forest adjacent to Ivory Nelson Center for the Sciences at Lincoln University, Pennsylvania (latitude $41^{\circ} 16^{\prime} 14.28^{\prime \prime S}$ and longitude $173^{\circ} 17^{\prime} 2.27^{\prime \prime E}$ ). They were identified by the color of their sporocarps, spore print, types of pore, and other standard descriptions of Alexopolous et al. [17] Webster and Weber [21]. The fruit bodies were air-dried on the laboratory bench and oven dried to constant weight at $45{ }^{\circ} \mathrm{C}$. The dried samples were pulverized in a Waring blender. Powdered samples were placed in sterile bottles and refrigerated at $4{ }^{\circ} \mathrm{C}$ until used.

Ground sample of Trichaptum biforme and Bjerkandera adusta were extracted using sterile distilled water, $95 \%$ ethanol and $95 \%$ methanol. Extraction was carried out by mixing 1.0 gram of each of the fungal samples with $10 \mathrm{ml}$ of each of the three solvents in sterile plastic tubes. The tubes were placed in a gyrating incubator which was set at $150 \mathrm{rpm}$ and $25^{\circ} \mathrm{C}$ for $48 \mathrm{hrs}$. Fungal extracts were then obtained by centrifugation at $25{ }^{\circ} \mathrm{C}$ and 3,000 rpm for 20 minutes. The supernatant of each extract obtained after centrifugation was sterilized by passing through a $0.22 \mu \mathrm{m}$ membrane filter. The fungal extracts were then dried at $45^{\circ} \mathrm{C}$ before re-suspension with $5 \mathrm{ml}$ of the same solvent used for extraction to obtain a dilution of $1 / 5(200 \mathrm{mg} / \mathrm{ml})$.

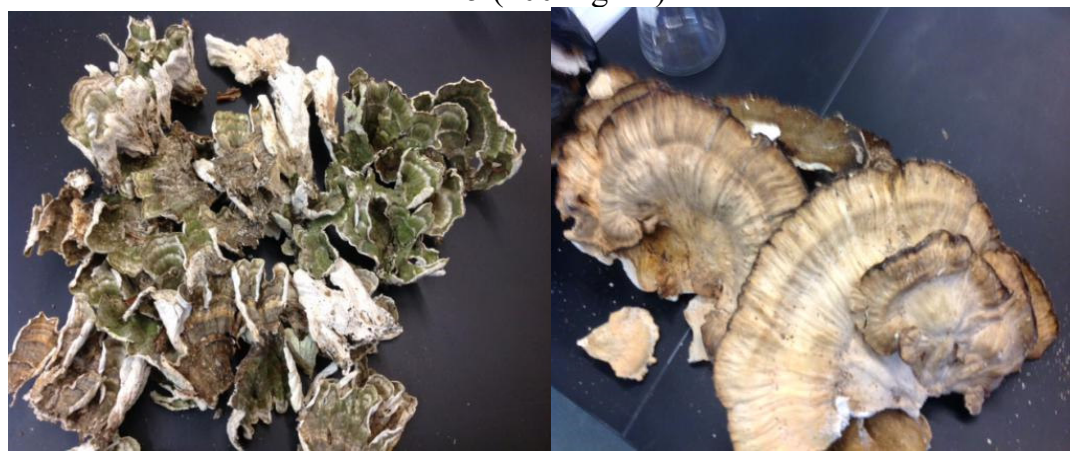

Fig. 1: Trichaptum biforme

Fig. 2: Bjerkandera adusta

The assay for antimicrobial activities was achieved using three Gram-positive bacteria; Staphylococcus aureus (85W1941), Staphylococcus epidermidis (85W1940) and Bacillus cereus (85W1815); and three Gramnegative bacteria, Escherichia coli (85W1860), Salmonella typhimurium (85W1956) and Pseudomonas aeruginosa (85W1903). The only fungus used for the study was Candida albicans (85W4150). These microorganisms were obtained from WARD'S Natural Science, Rochester, New York. USA (Latitude 43.1547222; Longitude 77.6158333).

Overnight cultures of Staphylococcus aureus, Staphylococcus epidermidis, Bacillus cereus, Escherichia coli, Salmonella typhimurium, Pseudomonas aeruginosa and Candida albicans were each suspended in tubes of sterile normal saline solution to a turbidity equivalent to $0.5 \mathrm{McFarland}$. Sterile cotton swabs were dipped in each suspension, and used to smear the surfaces of Mueller-Hinton agar until dry. The antimicrobial effects of aqueous, ethanol and methanol extracts of the fungal extracts were evaluated on each of the smeared microorganism using the agar well diffusion technique. For each organism smeared on Muller-Hinton agar, three wells were punched using sterile $6.0 \mathrm{~mm}$ cork-borer. The agar within the wells was carefully and aseptically removed, and $50 \mu \mathrm{L}$ of the appropriate solvent (distilled water; $95 \%$ ethanol; $95 \%$ methanol) was pipetted into the center well to serve as control. Fifty microliters $(50 \mu \mathrm{L})$ each of the extract of same solvent was also pipetted into the remaining wells. The plates were left on laboratory bench for one hour before incubation at $37^{\circ} \mathrm{C}$ for 24 hours. Zones of inhibition were measured with a caliper and metric ruler.

Minimum bactericidal concentration of each extract was determined on the susceptible bacteria by doubling dilution (1/5 to 1/1028) of the extracts using same solvent of extraction and the agar well diffusion technique. Cultures of the test microorganisms: Staphylococcus aureus, Staphylococcus epidermidis, Bacillus cereus, Escherichia coli, Salmonella typhimurium, Pseudomonas aeruginosa were each suspended in tubes of sterile saline solution to a turbidity of equivalent to $0.5 \mathrm{McFarland}$. Sterile cotton swabs were dipped in each suspension, and used to thoroughly smear the surfaces of Mueller-Hinton agar until dry. For each bacterial smear on Muller-Hinton agar, nine holes were punched using $6 \mathrm{~mm}$ cork-borer. The agar within the holes were carefully and aseptically removed, and $50 \mu \mathrm{l}$ of the $1 / 5$ dilution $(10 \mathrm{mg})$ was placed into the center well. The other extract dilutions of same solvent were pipetted into the remaining wells. The plates were allowed to sit at room temperature for one hour 
before incubation at $37^{\circ} \mathrm{C}$ for 24 hours. Zones of inhibition were measured with a caliper and metric rule.

\section{Results}

Results of this study show that aqueous, methanol and ethanol extracts of Trichaptum biforme and Bjerkandera adusta exhibited no antimicrobial activities against Candida albicans. Some extracts of $B$. adusta were however effective against all three Gram-negative bacteria and three Gram-positive bacteria. Some extracts of Trichaptum biforme were also effective against all three Gram-positive bacteria and only one Gram-negative bacterium, Escherichia coli.

Table 1 shows that the methanol, ethanol and aqueous extracts of $B$. adusta were effective against all the three Gram positive bacteria; Staphylococcus aureus, Staphylococcus epidermidis, Bacillus cereus, and one Gram negative bacterium, Escherichia coli. Pseudomonas aeruginosa was susceptible against methanol and ethanol extracts, but not the aqueous extract. On the other hand, Salmonella typhimurium was susceptible to the aqueous and methanol extracts of $B$. adusta, but was resistant to the ethanol extract.

The methanol extract of T. biforme was effective against Staphylococcus aureus, Staphylococcus epidermidis, Bacillus cereus and Escherichia coli. The ethanol extract was only effective against Bacillus cereus. Salmonella typhimurium and Pseudomonas aeruginosa were not susceptible to the aqueous, methanol and ethanol extract of T. biforme.

Table 2 shows the minimum inhibitory concentration of aqueous, methanol and ethanol extracts of Trichaptum biforme and Bjerkandera adusta on Staphylococcus aureus. The results show that only the methanol extract of Trichaptum biforme was effective against Staphylococcus aureus with MBC of $0.0391 \mathrm{mg}$; the aqueous and ethanol extracts had no antibacterial effect against Staphylococcus aureus. On the other hand, the aqueous, methanol and ethanol extracts of Bjerkandera adusta showed antibacterial activity against Staphylococcus aureus. The MBC of the aqueous extract of was $0.313 \mathrm{mg}$; that of the methanol and ethanol extracts was 0.0391 .

Table 3 shows the results of the MBC of aqueous, methanol and ethanol extracts of T. biforme and B. adusta on Staphylococcus epidermidis. Whereas, all three extracts of B. adusta were effective against Staphylococcus epidermidis, the methanol extract was most effective with an MBC of $0.0391 \mathrm{mg}$. The MBC for aqueous and ethanol extracts was $0.1563 \mathrm{mg}$. On the other hand, Staphylococcus epidermidis was susceptible to only the methanol extract of T. biforme with MBC of $0.0781 \mathrm{mg}$. The aqueous and ethanol extracts of T. biforme had no antibacterial activity against Staphylococcus epidermidis.

Table 4 shows the results of the MBC of aqueous, methanol and ethanol extracts of T. biforme and B. adusta on $B$. cereus. The results show that all three extracts of $B$. adusta were effective against $B$. cereus; however, the methanol extract of $B$. adusta was most effective with MBC of $0.0781 \mathrm{mg}$, followed by the aqueous extract with MBC of $0.1563 \mathrm{mg}$ and ethanol extract with $\mathrm{MBC}$ of $0.313 \mathrm{mg}$. On the other hand, the aqueous extract of $T$. biforme had no antibacterial activity against Bacillus cereus. The ethanol extract of $T$. biforme was more effective with $\mathrm{MBC}$ of $0.0391 \mathrm{mg}$ while the $\mathrm{MBC}$ of the methanol extract was $0.1563 \mathrm{mg}$. Table 5 shows the results of the MBC of aqueous, methanol and ethanol extracts of T. biforme and B. adusta on E. coli. All three extracts of $B$. adusta were effective against Escherichia coli; however, the aqueous and ethanol extracts were more effective with MBC of $0.1563 \mathrm{mg}$; MBC of methanol extract was higher at $0.313 \mathrm{mg}$.

On the other hand, aqueous and ethanol extracts of $T$. biforme had no antibacterial activity against $E$. coli. The methanol extract of $T$. biforme was effective with $\mathrm{MBC}$ of $0.0781 \mathrm{mg}$. Table 6 shows the results of the MBC of aqueous, methanol and ethanol extracts of $T$. biforme and B. adusta on P. aeruginosa. None of the extracts of $T$. biforme had any antibacterial activity against $P$. aeruginosa. The aqueous extract of $B$. adusta also did not have any antibacterial activity against $P$. aeruginosa. Methanol and ethanol extracts of $B$. adusta were however effective against $P$. aeruginosa; ethanol extract was more effective with $\mathrm{MBC}$ of $0.313 \mathrm{mg}$ while the methanol extract was only effective at $10 \mathrm{mg}$. Table 7 shows the results of the $\mathrm{MBC}$ of aqueous, methanol and ethanol extracts of T. biforme and B. adusta on Salmonella typhimurium. The results show that none of the extracts of $T$. biforme was effective against Salmonella typhimurium. On the other hand, the aqueous and methanol extracts of B. adusta exhibited antibacterial activity against Salmonella typhimurium. The MBC for the aqueous extract was $2.5 \mathrm{mg}$ while that of the methanol extract was $1.25 \mathrm{mg}$. 
Table 1: Antibacterial effect of aqueous, methanol and ethanol extracts on test bacteria (mm)

\begin{tabular}{ccccc}
\hline Test Bacteria & Fungal Extract & Water & Methanol & Ethanol \\
\hline S. aureus & Trichaptum biforme & 0.00 & 36.00 & 0.00 \\
& Bjerkandera adusta & 25.00 & 35.00 & 32.00 \\
S. epidermidis & Trichaptum biforme & 0.00 & 36.00 & 0.00 \\
& Bjerkandera adusta & 31.00 & 36.00 & 32.00 \\
B. cereus & Trichaptum biforme & 0.00 & 25.00 & 30.00 \\
& Bjerkandera adusta & 22.00 & 25.00 & 28.00 \\
E. coli & Trichaptum biforme & 0.00 & 32.00 & 0.00 \\
& Bjerkandera adusta & 28.00 & 28.00 & 32.00 \\
S. typhimurium & Trichaptum biforme & 0.00 & 0.00 & 0.00 \\
& Bjerkandera adusta & 20.00 & 25.00 & 0.00 \\
P. Aeruginosa & Trichaptum biforme & 0.00 & 0.00 & 0.00 \\
& Bjerkandera adusta & 0.00 & 20.00 & 30.00 \\
\hline
\end{tabular}

Table 2: MBC of aqueous, methanol and ethanol extracts of $T$. biforme and B. adusta on Staphylococcus aureus

\begin{tabular}{|c|c|c|c|c|c|c|c|c|c|c|}
\hline \multirow{2}{*}{$\begin{array}{c}\text { Extracts } \\
\text { (mm) }\end{array}$} & \multirow{2}{*}{ Test Fungi } & \multicolumn{9}{|c|}{ Concentrations (mg) } \\
\hline & & 10 & 5 & 2.5 & 1.25 & 0.625 & 0.313 & 0.1563 & 0.0781 & 0.0391 \\
\hline \multirow[t]{2}{*}{ Water } & $\begin{array}{c}\text { Trichaptum } \\
\text { biforme }\end{array}$ & 0.00 & 0.00 & 0.00 & 0.00 & 0.00 & 0.00 & 0.00 & 0.00 & 0.00 \\
\hline & $\begin{array}{c}\text { Bjerkander } \\
\text { a adusta }\end{array}$ & 25.00 & 23.00 & 19.00 & 17.00 & 14.00 & 10.00 & 0.00 & 0.00 & 0.00 \\
\hline \multirow[t]{2}{*}{ Methanol } & $\begin{array}{c}\text { Trichaptum } \\
\text { biforme }\end{array}$ & 36.00 & 31.00 & 25.00 & 22.00 & 19.00 & 18.00 & 15.00 & 13.00 & 9.00 \\
\hline & $\begin{array}{c}\text { Bjerkander } \\
\text { a adusta }\end{array}$ & 35.00 & 31.00 & 22.00 & 20.00 & 19.00 & 18.00 & 15.00 & 13.00 & 0.00 \\
\hline \multirow[t]{2}{*}{ Ethanol } & $\begin{array}{c}\text { Trichaptum } \\
\text { biforme }\end{array}$ & 0.00 & 0.00 & 0.00 & 0.00 & 0.00 & 0.00 & 0.00 & 0.00 & 0.00 \\
\hline & $\begin{array}{c}\text { Bjerkander } \\
\text { a adusta }\end{array}$ & 32.00 & 28.00 & 27.00 & 26.00 & 20.00 & 20.00 & 16.00 & 12.00 & 0.00 \\
\hline
\end{tabular}

Table 3: MBC of aqueous, methanol and ethanol extracts of T. biforme and B. adusta on Staphylococcus epidermidis

\begin{tabular}{ccccccccccc}
\hline \multirow{2}{*}{ Extracts (mm) } & \multicolumn{1}{c}{ Concentrations (mg) } \\
& \multirow{2}{*}{ Test Fungi } & $\mathbf{1 0}$ & $\mathbf{5}$ & $\mathbf{2 . 5}$ & $\mathbf{1 . 2 5}$ & $\mathbf{0 . 6 2 5}$ & $\mathbf{0 . 3 1 3}$ & $\mathbf{0 . 1 5 6 3}$ & $\mathbf{0 . 0 7 8 1}$ & $\mathbf{0 . 0 3 9 1}$ \\
\hline \multirow{2}{*}{ Water } & Trichaptum biforme & 0.00 & 0.00 & 0.00 & 0.00 & 0.00 & 0.00 & 0.00 & 0.00 & 0.00 \\
& Bjerkandera adusta & 31.00 & 30.00 & 24.00 & 24.00 & 19.00 & 13.00 & 10.00 & 0.00 & 0.00 \\
\multirow{3}{*}{ Eethanol } & Trichaptum biforme & 36.00 & 30.00 & 28.00 & 26.00 & 24.00 & 18.00 & 12.00 & 10.00 & 0.00 \\
& Bjerkandera adusta & 36.00 & 36.00 & 30.00 & 26.00 & 24.00 & 20.00 & 16.00 & 14.00 & 10.00 \\
& Trichaptum biforme & 0.00 & 0.00 & 0.00 & 0.00 & 0.00 & 0.00 & 0.00 & 0.00 & 0.00 \\
& Bjerkandera adusta & 32.00 & 30.00 & 28.00 & 22.00 & 18.00 & 14.00 & 12.00 & 0.00 & 0.00 \\
\hline
\end{tabular}

Table 4: MBC of aqueous, methanol and ethanol extracts of $T$. biforme and B. adusta on B. cereus

\begin{tabular}{lcrrrrrrrrr}
\hline \multirow{2}{*}{ Extracts (mm) } & \multirow{2}{*}{ Test Fungi } & $\mathbf{1 0}$ & $\mathbf{5}$ & $\mathbf{2 . 5}$ & $\mathbf{1 . 2 5}$ & $\mathbf{0 . 6 2 5}$ & $\mathbf{0 . 3 1 3}$ & $\mathbf{0 . 1 5 6 3}$ & $\mathbf{0 . 0 7 8 1}$ & $\mathbf{0 . 0 3 9 1}$ \\
\cline { 2 - 11 } & Trichaptum biforme & 0.00 & 0.00 & 0.00 & 0.00 & 0.00 & 0.00 & 0.00 & 0.00 & 0.00 \\
\multirow{3}{*}{ Wethanol } & Bjerkandera adusta & 22.00 & 22.00 & 20.00 & 18.00 & 17.00 & 15.00 & 10.00 & 0.00 & 0.00 \\
& Trichaptum biforme & 25.00 & 21.00 & 19.00 & 16.00 & 15.00 & 12.00 & 10.00 & 0.00 & 0.00 \\
\multirow{2}{*}{ Ethanol } & Bjerkandera adusta & 30.00 & 24.00 & 20.00 & 20.00 & 16.00 & 14.00 & 13.00 & 10.00 & 0.00 \\
& Trichaptum biforme & 30.00 & 30.00 & 30.00 & 26.00 & 22.00 & 20.00 & 14.00 & 10.00 & 7.00 \\
& Bjerkandera adusta & 28.00 & 24.00 & 18.00 & 18.00 & 17.00 & 15.00 & 0.00 & 0.00 & 0.00 \\
\hline
\end{tabular}


Table 5: MBC of aqueous, methanol and ethanol extracts of $T$. biforme and B. adusta on $E$. coli

\begin{tabular}{|c|c|c|c|c|c|c|c|c|c|c|}
\hline \multirow{2}{*}{ Extracts (mm) } & \multirow{2}{*}{ Test Fungi } & \multicolumn{9}{|c|}{ Concentrations (mg) } \\
\hline & & 10 & 5 & 2.5 & 1.25 & 0.625 & 0.313 & 0.1563 & 0.0781 & 0.0391 \\
\hline \multirow[t]{2}{*}{ Water } & Trichaptum biforme & 0.00 & 0.00 & 0.00 & 0.00 & 0.00 & 0.00 & 0.00 & 0.00 & 0.00 \\
\hline & Bjerkandera adusta & 28.00 & 25.00 & 20.00 & 15.00 & 15.00 & 8.00 & 8.00 & 0.00 & 0.00 \\
\hline \multirow[t]{2}{*}{ Methanol } & Trichaptum biforme & 32.00 & 28.00 & 22.00 & 19.00 & 19.00 & 15.00 & 13.00 & 7.00 & 0.00 \\
\hline & Bjerkandera adusta & 28.00 & 28.00 & 22.00 & 18.00 & 16.00 & 13.00 & 0.00 & 0.00 & 0.00 \\
\hline \multirow[t]{2}{*}{ Ethanol } & Trichaptum biforme & 0.00 & 0.00 & 0.00 & 0.00 & 0.00 & 0.00 & 0.00 & 0.00 & 0.00 \\
\hline & Bjerkandera adusta & 32.00 & 22.00 & 22.00 & 20.00 & 14.00 & 14.00 & 12.00 & 0.00 & 0.00 \\
\hline
\end{tabular}

Table 6: MBC of aqueous, methanol and ethanol extracts of $T$. biforme and $B$. adusta on $P$. aeruginosa

\begin{tabular}{|c|c|c|c|c|c|c|c|c|c|c|}
\hline \multirow{2}{*}{ Extracts (mm) } & \multirow{2}{*}{ Test Fungi } & \multicolumn{9}{|c|}{ Concentrations (mg) } \\
\hline & & 10 & 5 & 2.5 & 1.25 & 0.625 & 0.313 & 0.1563 & 0.0781 & 0.0391 \\
\hline \multirow[t]{2}{*}{ Water } & Trichaptum biforme & 0.00 & 0.00 & 0.00 & 0.00 & 0.00 & 0.00 & 0.00 & 0.00 & 0.00 \\
\hline & Bjerkandera adusta & 0.00 & 0.00 & 0.00 & 0.00 & 0.00 & 0.00 & 0.00 & 0.00 & 0.00 \\
\hline \multirow[t]{2}{*}{ Methanol } & Trichaptum biforme & 0.00 & 0.00 & 0.00 & 0.00 & 0.00 & 0.00 & 0.00 & 0.00 & 0.00 \\
\hline & Bjerkandera adusta & 20.00 & 0.00 & 0.00 & 0.00 & 0.00 & 0.00 & 0.00 & 0.00 & 0.00 \\
\hline \multirow[t]{2}{*}{ Ethanol } & Trichaptum biforme & 0.00 & 0.00 & 0.00 & 0.00 & 0.00 & 0.00 & 0.00 & 0.00 & 0.00 \\
\hline & Bjerkandera adusta & 30.00 & 20.00 & 18.00 & 12.00 & 12.00 & 11.00 & 0.00 & 0.00 & 0.00 \\
\hline
\end{tabular}

Table 7: MBC of aqueous, methanol and ethanol extracts of T. biforme and B. adusta on Salmonella typhimurium

\begin{tabular}{|c|c|c|c|c|c|c|c|c|c|c|}
\hline \multirow{2}{*}{ Extracts (mm) } & \multirow{2}{*}{ Test Fungi } & \multicolumn{9}{|c|}{ Concentrations (mg) } \\
\hline & & 10 & 5 & 2.5 & 1.25 & 0.625 & 0.313 & 0.1563 & 0.0781 & 0.0391 \\
\hline \multirow[t]{2}{*}{ Water } & Trichaptum biforme & 0.00 & 0.00 & 0.00 & 0.00 & 0.00 & 0.00 & 0.00 & 0.00 & 0.00 \\
\hline & Bjerkandera adusta & 20.00 & 15.00 & 10.00 & 0.00 & 0.00 & 0.00 & 0.00 & 0.00 & 0.00 \\
\hline \multirow[t]{2}{*}{ Methanol } & Trichaptum biforme & 0.00 & 0.00 & 0.00 & 0.00 & 0.00 & 0.00 & 0.00 & 0.00 & 0.00 \\
\hline & Bjerkandera adusta & 25.00 & 20.00 & 15.00 & 13.00 & 0.00 & 0.00 & 0.00 & 0.00 & 0.00 \\
\hline \multirow[t]{2}{*}{ Ethanol } & Trichaptum biforme & 0.00 & 0.00 & 0.00 & 0.00 & 0.00 & 0.00 & 0.00 & 0.00 & 0.00 \\
\hline & Bjerkandera adusta & 0.00 & 0.00 & 0.00 & 0.00 & 0.00 & 0.00 & 0.00 & 0.00 & 0.00 \\
\hline
\end{tabular}

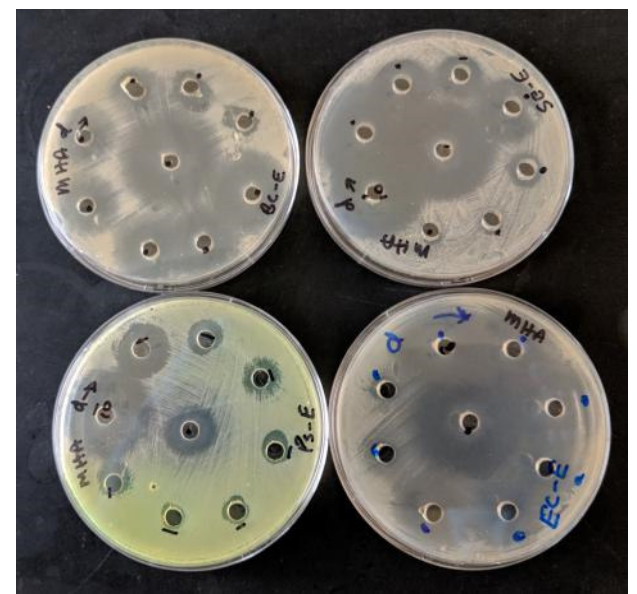

Fig. 3: Agar plates of MBC: Ethanol extract of B. adusta

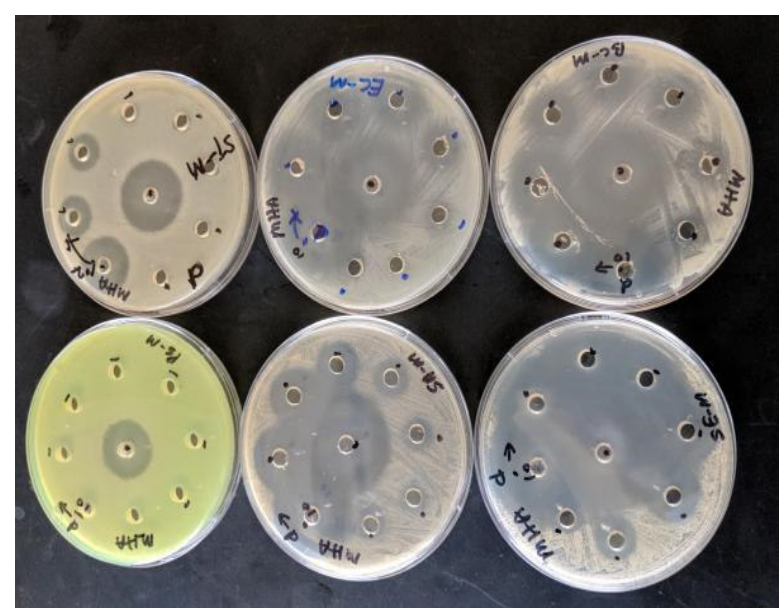

Fig. 4: Agar plates of MBC: Methanol extract of B. adusta 


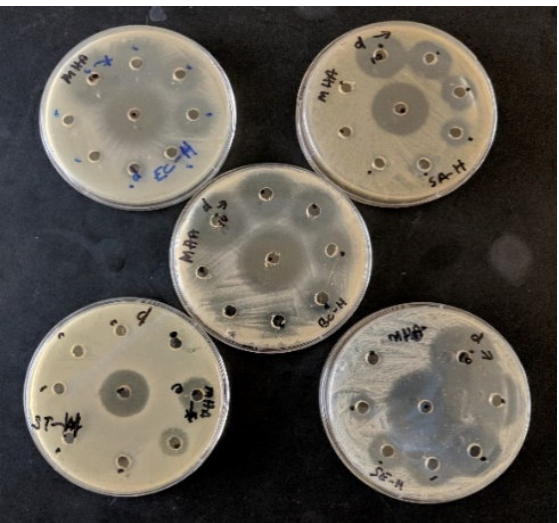

Fig. 5: Agar plates of MBC: Water extract of $B$. adusta

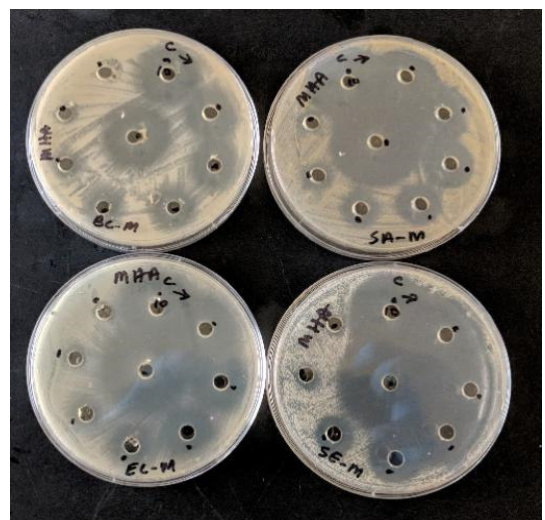

Fig. 6: Agar plates of MBC: Methanol extract of T. biforme

\section{Discussion}

Species composition and richness of some polyroid macrofungi have been studies in the US [22-25], and this group of fungi has generally been used as ecosystem indicators. However, therapeutic effects of many macrofungi have been well documented. The natural defensive mechanism of fungi against different pathogenic organisms can be associated with their capabilities in producing different antibiotics and accumulation of different phytochemicals in their tissues. These chemicals have been extracted by different scientists, many of which have proven to inhibit several viruses, bacteria or fungi pathogens with low or no cytotoxicity to human or other animal hosts.

Our results indicate that Candida albicans was not susceptible to the aqueous, ethanol and methanol extracts of Trichaptum biforme and Bjerkandera adusta. This implies that T. biforme and B. adusta extracts lack antifungal activity, but possess antibacterial activity. Similar resistance of Candida albicans to methanol extracts of Boletus lupinus, Flammulina velutypes, Phellinus igniarius, Sarcodon imbricatus, Tricholoma aurantium and Xerocomus ichnusanus have been reported by Nedelkoska et al. [27]. Another report from Nigeria also showed that Candida albicans was not susceptible to the methanol extracts of Fomes lignosus, Marasmius jodocodo, Pleurotus florida, Plurotus tuber-regium, Psathyrella atroumbonata, Termitomyces microcarpus and Termitomyces robustus [26].

In an in-vitro study, extracts of several polypore mushrooms were tested and 75 percent of them were confirmed to show antimicrobial activities against wide range of microorganisms [28]. Similar observation was made by Ranadive et al. [29], but reported that little has been reported among verse species of fungi that possess antimicrobial activities. Our results however, showed clear antibacterial effects of Trichaptum biforme and Bjerkandera adusta extracts. This is in agreement with the reports of other authors that pathogenic bacteria are generally more susceptible to mushrooms and other macrofungal extracts compared with fungi $[6,10]$.

\section{Conclusion}

The nutritive effect of many mushrooms have been well identified, their therapeutic effect has also been identified for many years however, antimicrobial potentials of many polypore mushrooms have not been well documented and exploited. In this study, extracts of Trichaptum biforme and Bjerkandera adusta showed strong antibacterial effects against selected Gram positive and Gram negative bacteria. Further studies are planned on the appropriate utilization of these extracts as antimicrobial agents coupled with techniques for mass cultivation of these fungi in controlled environments.

\section{Declaration of competing interest}

Authors declare no conflict of interest on this manuscript

\section{Acknowledgments.}

We are thankful to IIE New York for granting Dr. Gbolagade Jonathan a Fulbright Fellowship. This study was also supported by Lincoln's Excellent Academic Program in Science - Transformation (LEAPS-T) funded by the National Science Foundation Grant \# 92-1583.

\section{References}

1. Jonathan, S.G., Amos-Tautua, B.M.W., Olawuyi, O.J. (2011). Food values, heavy metal accumulation, aflatoxin contamination and detection of exo-polysaccharrides in Lentinus Squarrosulus Berk, a Nigerian mushroom. African Journal of Agricultural Research 6(13), 3007-3012.

2. Oluranti, O.O., Jonathan, S.G., Olawuyi, O.J. (2018), Prophylactic effects of some Nigerian higher fungi on malaria parasite, Plasmodium berghei berghei in BALB/c strain albino mice. Journal of Advances in Biology 
\& Biotechnology 20(3), 1-13

3. Chikwem, J., Jonathan, G., Hull, A., Asemoloye, M., Omuero, R., Tanny, P.C. (2019), Comparative studies on antimicrobial potentials of Daedalea quercina and Tramates pubescens. IHE: Lincoln University Journal of Science; 8: 22-29.

4. Gbolagade, J.S., Ajayi, A.I., Oku, I., Wankasi, D.O. (2006), Nutritive value of common wild edible mushrooms from southern Nigeria. Global Journal of Biotechnology and Biochemistry 1(1), 16-21

5. Jonathan, S.G., Okon, C.B., Oyelakin, A.O. \& Oluranti, O.O. (2012a), Nutritional values of oyster mushroom (Pleurotus ostreatus) (Jacq. Fr.) Kumm. cultivated on different agricultural wastes. Nature and Science; 10(9), 186-191.

6. Wasser, S.P., \& Weis, A.L. (1999), Therapeutic effects of substances occurring in higher Basidiomycetes mushrooms: a modern perspective. Crit. Rev. Immunol. 19, 65-96.

7. Lindequist, U., Niedermeyer, T.H.J., \& Julich, W.D. (2005), The Pharmacological potential of mushrooms. eCAM. 2, 285-299.

8. Oluranti, O.O., Olawuyi, O.J., \& Jonathan, S.G. (2012), Therapeutic properties of some Nigerian higher fungi. Nature and Science 10(10), 135-143.

9. Jonathan, S.G., Nwokolo, V.M., Ekpo, E.N., Olawuyi, O.J., \& Babalola, B.J. (2013), Effect of phytochemical composition of agricultural wastes on yield and proximate compositions of Pleurotus pulmonarius (fries.) que'let. NPAIJ 9(4), 123-132.

10. Agbawodike, C.R., Sobowale, A.A, Gbolagade, J., Aguzie, S., \& Ifeanyi, O.N. (2018), In vitro inhibitory potentials of aqueous and ethanol extracts of Hyptis suaveolens on fungi associated with postharvest spoilage of Brassica oleracea. African J. Biotechnol. 17(31), 949-95.

11. Anke, T. (1989), Basidiomycetes: A source for new bioactive secondary metabolites. Prog. Ind. Microbiol. 27, 51-66.

12. Quang, D.N., Hashimoto, T., Asakawa, Y. (2006), Inedible mushrooms: A good source of biologically active substances. Chem. Record 6, 79-99.

13. Jonathan, S.G. (2019), Fungi here, fungi there, fungi everywhere: unique and unparalleled contributions of fungi to environment, food production and medicine. Inaugural lecture. University of Ibadan, Ibadan, Nigeria. ISBN978-978-8529-88-0. (91 Pages)

14. Jonathan, G., Chikwem, J., Hull, A., Abdul-Lateef, N., Omuero, R., \& Tanny, P.C. 2019. Antimicrobial activity of Pleurotus pulmonarius and Coprinus sterquilinus collected from Lincoln University campus. IHE: Lincoln University Journal of Science. 8, 14-21.

15. Jonathan, S.G., \& Awotona, F.E. (2010). Studies on Antimicrobial Potentials of three Ganoderma species. African Journal of Biomedical Research 13, 133-139.

16. Jonathan, S.G., Olawuyi, O.J., \& Oluranti, O.O. (2012b), Studies on Imunomodulatory and prophylactic properties of some wild Nigerian mushrooms. Academia Arena 4(9): 39-45.

17. Alexopoulos, C.J., Mims, C.W., \& Blackwell, M.M. (1996), Introductory Mycology. $4^{\text {th }}$ Edition. John Wiley and Sons, New York, USA. 868p.

18. Kuo, M. (2004), Trichaptum biforme. Retrieved from the MushroomExpert.Com Web site: http://www.mushroomexpert.com/trichaptum_biforme.html

19. Ostry, M.E., Anderson, N.A., \& O’Brien, J.G. (2011), Field guide to common macro-fungi in Eastern forests and their ecosystem functions. U.S. Forest service. Forest service 11 Campus Blvd Suite 200 publications distribution Newtown Square, PA. 19073, 90.

20. Francisco, J., Ruiz-Dueñas, T.L., Dimitrios Floudas, Laszlo, G. Nagy, José, M. Barrasa, David S. H., Angel, T. M. (2013), Lignin-degrading peroxidases in Polyporales: an evolutionary survey based on 10 sequenced genomes, Mycologia 105(6), 1428-1444, DOI: 10.3852/13-059

21. Webster, J., \& Weber, R. (2007), Introduction to Fungi. Cambridge University Press. pp. 536-537. ISBN 978-1-139-46150-4.

22. Bader, P., Jansson, S., \& Jonsson B.G. (1995), Wood-inhabiting fungi and substratum decline in selectively logged boreal spruce forests. Biological Conservation 72, 355-362

23. Berglund, H., Edman, M., \& Ericson, L. (2005), Temporal variation of wood-fungi diversity in boreal oldgrowth forests: implications for monitoring Ecological Applications 15, 970-982.

24. Stokland, J.N., \& Larsson K.H. (2011). Legacies from natural forest dynamics: different effects of forest management on wood-inhabiting fungi in pine and spruce forests Forest Ecology and Management 261, 1707-1721

25. Frieden, T. (2013), Antibiotic Resistance Threats in the United. Stateshttp:/www.cdc.gov/drugresistance/threat-report-2013/pdf/ar-threats-2013-508.pdf

26. Gbolagade, J., Kigigha, L., \& Ohimain, E. (2007), Antagonistic effect of extracts of some Nigerian higher fungi against selected pathogenic microorganisms. Amer-Eurasian Journal of Agricultural and Environmental Science 2, 364-368. 
27. Nedelkoska DN, Pancevska NA, Amedi H, Veleska D, Ivanova E, Karadelev M., et al. (2013), Screening of antibacterial and antifungal activities of selected 486 Macedonian wild mushrooms. Journal of Natural Sciences 124: 333-340.

28. Suay, I., Arenal, F., Asensio, F.J., Basilio, A., Cabello, M.A., Díez, M.T., García, J.B., Val, A.G., Gorrochategui, J., Hernández, P., Peláez, F., \& Vicente, M.F. (2000), Screening of basidiomycetes for antimicrobial activities. Antonie Van Leeuwenhoek 78, 129- 139.

29. Ranadive K.R., Belsare M.H. Deokule S.S. Jagtap N.V. Jadhav H.K., \& Vaidy J.G. (2013), Glimpses of antimicrobial activity of fungi from World. Journal on New Biological Reports 2(2), 142-162. 